Original Article

\title{
Enhancing The Role of Business in Transferring Research Results into Agriculture: Case Study in Moc Chau District, Son La Province
}

\author{
Ngo Thi Phuong Quy* \\ Vietnam Academy For Ethnic Minorities (VAEM), DreamTown-COMA6, 70 Street, \\ Tay Mo, Nam Tu Liem, Hanoi, Vietnam
}

Received 11 March 2020

Revised 19 March 2020; Accepted 25 March 2020

\begin{abstract}
In recent years, Vietnam's agriculture has developed strongly thanks to the application of scientific and technological advances in production. Business is a key factor in attracting investment, expanding markets for agricultural products, and an important focal point for transferring research results into agriculture. Based on the assessment of the status of transferring research results into agriculture in Moc Chau district, Son La province over the past time, the paper proposes views and solutions to enhance the role of business in promoting the transfer of research results in local agriculture such as tax favors for business, linkages between business and researchers and enhance the quality of human resources.
\end{abstract}

Keywords: Transferring research results, Agriculture, Business.

\footnotetext{
* Corresponding author.

E-mail address: quyntp@hvdt.edu.vn
}

https://doi.org/10.25073/2588-1116/vnupam.4216 


\title{
VNU Journal of Science: Policy and Management Studies Nâng cao vai trò của doanh nghiệp trong chuyển giao kết quả nghiên cứu vào nông nghiệp: Nghiên cứu trường hợp huyện Mộc Châu, tỉnh Sơn La
}

\author{
Ngô Thị Phương Quý* \\ Học viện Dân tộc, Khu đô thị Dream Town, Đường 70, Tây Mỗ, Nam Tù Liêm, Hà Nội, Việt Nam \\ Nhận ngày 24 tháng 2 năm 2020 \\ Chỉnh sửa ngày 21 tháng 3 năm 2020; Chấp nhận đăng ngày 24 tháng 3 năm 2020
}

\begin{abstract}
Tóm tắt: Trong những năm gần đây, nền nông nghiệp của nước ta đã phát triển mạnh mẽ nhờ ứng dụng những tiến bộ của khoa học và công nghệ vào trong sản xuất. Doanh nghiệp chính là nhân tố then chốt trong việc thu hút đầu tư, mở rộng thị trường tiêu thụ hàng nông sản, là đầu mối quan trọng cho việc chuyển giao kết quả nghiên cứu vào trong nông nghiệp. Trên cơ sở đánh giá thực trạng hoạt động chuyển giao các kết quả nghiên cứu trong nông nghiệp ở Mộc Châu, Sơn La thời gian qua, bài viết đề xuất các quan điểm và giải pháp nhằm nâng cao vai trò của doanh nghiệp trong việc thúc đẩy chuyển giao kết quả nghiên cứu trong nông nghiệp tại địa phương như ưu đãi thuế cho doanh nghiệp, thúc đẩy mối liên kết giữa doanh nghiệp và nhà nghiên cứu, nâng cao chất lượng nguồn nhân lực.
\end{abstract}

Từ khóa: Chuyển giao kết quả nghiên cứu, Nông nghiệp, Doanh nghiệp

\section{Mở đầu}

Trong nền kinh tế quốc dân, nông nghiệp đóng vai trò rất quan trọng. Nó tạo nên sự ồn định, đảm bảo an ninh lương thực cho đời sống xã hội, mở rộng hợp tác quốc tế thông qua xuất khẩu mặt hàng nông sản, đồng thời đóng góp nguồn ngân sách lớn cho nhà nước. Tuy nhiên, nền nông nghiệp nước ta hiện nay nhìn chung phát triển còn chậm, không đồng đều, canh tác còn lạc hậu đặc biệt là những vùng sâu, vùng

\footnotetext{
*Tác giả liên hệ.

Địa chỉ email: quyntp@hvdt.edu.vn
}

https://doi.org/10.25073/2588-1116/vnupam.4216 xa. Nhà nước ta đã có nhiều chính sách, chương trình, dự án lớn nhằm phát triển nông nghiệp, nông thôn trên cả nước, cũng như ban hành những chính sách cụ thể cho từng vùng. Thời gian qua, hoạt động chuyển giao kết quả nghiên cứu (CGKQNC) vào lĩnh vực nông nghiệp vùng Tây Bắc nói chung và tại Mộc Châu nói riêng, đã đem lại những hiệu quả nhất định, làm thay đổi diện mạo của ngành nông nghiệp. Các giống cây trồng có chất lượng cao, ngắn ngày, phù hợp với điều kiện tự nhiên được chuyển giao và đem lại hiệu quả kinh tế cao. Đặc biệt, với điều kiện khí hậu phù hợp với chăn nuôi đại gia súc, một số giống vật nuôi như trâu, bò, bò sữa ... được chuyển giao thành công, người dân 
đã mạnh dạn đầu tư để mở rộng quy mô sản xuất, thu nhập bình quân hàng triệu đồng/tháng. Mặc dù đạt được kết quả tốt nhưng hoạt động CGKQNC nhìn chung chưa được nhiều người quan tâm đến, đặc biệt là doanh nghiệp và người dân chưa thực sự hưởng ứng. Để cạnh tranh và tìm chỗ đứng của mình trên thị trường, doanh nghiệp luôn ưu tiên hoạt động đổi mới công nghệ, máy móc sản xuất hiện đại, tiên tiến nhằm tạo ra sản phẩm tốt nhất đến tay người tiêu dùng. Doanh nghiệp chính là yếu tố then chốt thúc đẩy phát triển thị trường khoa học và công nghệ (KH\&CN), giúp các kết quả nghiên cứu được chuyển giao, ứng dụng có hiệu quả vào thực tiễn. Vì vậy, việc đưa ra chính sách đổi mới nhằm hỗ trợ doanh nghiệp CGKQNC vào thực tiễn là rất cần thiết trong xu thế phát triển hiện nay.

\section{Thực trạng chuyển giao kết quả nghiên cứu vào nông nghiệp ở Mộc Châu, tỉnh Sơn La}

\subsection{Thực trạng chuyển giao kết quả nghiên cứu vào nông nghiệp}

Xác định được tầm quan trọng của việc chuyển giao kết quả nghiên cứu và ứng dụng những tiến bộ về khoa học và công nghệ vào lĩnh vực nông nghiệp, trong thời gian qua, tỉnh Sơn La đã có một số dự án tiêu biểu như năm 2017 và 2018, tỉnh Sơn La đã phê duyệt triển khai thực hiện 02 dự án từ nguồn cân đối ngân sách của tỉnh là Dự án Đầu tư xây dựng công trình nghiên cứu, ứng dụng, chuyển giao tiến bộ KH\&CN về nông, lâm nghiệp tại huyện Mộc Châu (Quyết định 2662/QĐ-UBND ngày 30/10/2015 của Ủy ban nhân dân tỉnh Sơn La) với quy mô 3,55 hecta, tổng mức đầu tư là 54 tỷ đồng, thực hiện trong giai đoạn 2016-2020 và Dự án Xây dựng trụ sở và tăng cường tiềm lực Trung tâm Thông tin và Thống kê KH\&CN với tổng kinh phí 14,9 tỷ đồng, thực hiện năm 2017-2018 [1].

Mộc Châu là huyện cửa ngõ đặc biệt quan trọng nằm ở phía Nam của tỉnh Sơn $\mathrm{La}$, với điều kiện tự nhiên, khí hậu độc đáo, nằm trong vùng khí hậu nhiệt đới gió mùa núi cao, mùa đông lạnh khô, mùa hè mát ẩm mưa nhiều nên nơi đây rất đa dạng về các giống cây trồng và vật nuôi. Trong những năm qua, cùng với chính sách phát triển của tỉnh, hoạt động sản xuất trong lĩnh vực nông nghiệp của huyện Mộc Châu đã có sự phát triển đáng kể, bước đầu thực hiện có hiệu quả việc chuyển đổi cơ cấu sản xuất theo hướng sản xuất hàng hóa, chú trọng nâng cao chất lượng sản phẩm nông nghiệp, từng bước hình thành vùng sản xuất tập trung trọng điểm. Theo thống kê của huyện Mộc Châu, trên địa bàn huyện hiện có trên 100 mô hình ứng dụng công nghệ sinh học, hơn 30 ha nhà lưới, nhà kính, gần 60 mô hình ứng dụng công nghệ tưới phun sương và tưới nhỏ giọt Isarel và 35 chuỗi tiêu thụ sản phẩm an toàn. Hiện tại, huyện Mộc Châu có 286 ha sản xuất theo quy trình VietGAP và GlobalGAP. Năm 2019, huyện Mộc Châu đã xuất khẩu gần 3.300 tấn nông sản, tổng giá trị trên 8 triệu USD, gồm chanh leo, chè các loại, rau an toàn, xoài, mận và một số sản phẩm nông sản khác [2]. Một số kết quả nghiên cứu được chuyển giao như xây dựng mô hình tưới nước tiết kiệm, mô hình bón phân cân đối và đặc biệt là mô hình tổng hợp quản lý bón phân, tưới nước và áp dụng quản lý dịch hại tổng hợp. Các hộ nông dân ở xã Bản Áng, Bó Bun, ... thực hiện ghi sổ nhật ký đồng thời theo dõi lịch tưới nước, bón phân, làm cỏ, phun thuốc bảo vệ thực vật... qua đó cuối vụ tính toán được hiệu quả kinh tế. Kỹ thuật bón phân trên cơ sở chuẩn đoán dinh dưỡng đất, dinh dưỡng lá, bón phân qua lá và công nghệ bón phân theo chẩn đoán và năng suất cây trồng cũng được nhiều nông hộ quan tâm. Đây là cơ sở ban đầu cho việc thực hành nông nghiệp tốt (GAP). Song song với việc chuyển giao thực hành nông nghiệp tốt, công nghệ xử lý vỏ cà phê làm phân bón thay thế phân chuồng đã được nông dân chấp nhận và đạt hiệu quả kinh tế cao trong sản xuất.

Một số kết quả nghiên cứu tiêu biểu được chuyển giao vào nông nghiệp như:

Trong trồng trọt :

1. Nghiên cứu chọn lọc và nhân giống khoai sọ Cụ Cang 
2. Ứng dụng công nghệ cao trồng thử nghiệm hoa ly tại Mộc Châu

3. Sản xuất chế phẩm vi sinh trong nông nghiệp và bảo vệ môi trường

4. Xây dựng mô hình trồng khảo nghiệm cây ăn quả ôn đới chất lượng cao

5. Mô hình sản xuất rau cao cấp ứng dụng công nghệ tiên tiến của Hà Lan

6. Tuyển chọn một số giống dưa vàng thơm Hà Lan tại Mộc Châu

7. Nghiên cứu khảo nghiệm một số giống dâu tây tại Mộc Châu

8. Mô hình trồng thử nghiệm giống hồng MC1 tại huyện Mộc Châu

Trong chăn nuôi:

1. Mô hình nuôi lợn rừng và lợn lai thương phẩm tại Sơn La

2. Ứng dụng quy trình kỹ thuật để sản xuất giống cá lăng tại Sơn La

3. Sản xuất giống nhím bờm tại Sơn La

4. Sản xuất giống cá chép lai, rô phi siêu đực và mô hình nuôi cá năng suất cao

5. Ứng dụng phương pháp kỹ thuật cấy chuyển phôi bò sữa thuần chủng

6. Ứng dụng KHKT lai tạo giống giữa bò thịt cao sản với bò cái lai zêbu

Một số công nghệ nước ngoài do các doanh nghiệp mua trực tiếp: Các công nghệ trong chăn nuôi bò sữa như máy cắt cỏ, máy vắt sữa, máy giàn, máy chế biến chè...[3]

Các chinh sách thúc đẩy CGKQNC vào lĩnh vục nông nghiệp trong thời gian qua

- Chính sách hỗ trợ chuyển giao công nghệ

Trong thời gian qua, các doanh nghiệp nhà nước được nhà nước hỗ trợ trực tiếp để đầu tư qua các kênh khác như viện, trung tâm nghiên cứu, các doanh nghiệp nước ngoài thì hoạt động nghiên cứu và $C G K Q N C$ của họ rất mạnh. Tuy nhiên, các doanh nghiệp nông nghiệp trên địa bàn huyện Mộc Châu rất khó tiếp cận sự hỗ trợ của nhà nước cho hoạt động CGKQNC, khó tiếp cận thông tin khoa học và thị trường công nghệ.

\section{- Chính sách thuế}

Luật KH\&CN quy định ưu đãi về thuế đối với các hoạt động KH\&CN của doanh nghiệp như các quy định về miễn thuế thu nhập doanh nghiệp. Các doanh nghiệp còn được miễn thuế nhập khẩu và thuế giá trị gia tăng cho việc nhập thiết bị công nghệ...

Tuy nhiên, các chính sách thuế hiện nay chưa đồng bộ và phức tạp. Chính điều này đã gây trở ngại cho việc thực hiện của doanh nghiệp nông nghiệp. Vì với trình độ năng lực và quản lý còn hạn hẹp của chủ và kế toán doanh nghiệp nông nghiệp hiện nay thì khó tránh khỏi việc gian lận thuế. Thuế thu nhập doanh nghiệp chiếm $32 \%$ lợi nhuận khá cao so với điều kiện hoạt động khó khăn và khả năng cạnh tranh non yếu của doanh nghiệp nhỏ và vừa nông nghiệp nông thôn, chưa khuyến khích được việc đầu tư tái sản xuất công nghệ.

- Chính sách nhân lực

Do nhiều nguyên nhân khác nhau dẫn đến các chính sách của nhà nước đem lại kết quả rất thấp. Trình độ văn hóa và chuyên môn của chủ doanh nghiệp hay công nhân rất hạn chế, chủ yếu hoạt động cầm chừng, truyền thống, sản xuất nhỏ lẻ nên khả năng tiếp cận với các chính sách hỗ trợ từ nhà nước hầu như là rất khó.

Một số doanh nghiệp lớn như Công ty Sữa Mộc Châu và Công ty Chè Mộc Châu là hoạt động theo hình thức cổ phần, hợp đồng khoán. Các hộ nông dân nuôi bò sữa và trồng chè (công nhân của công ty, hộ sản xuất nhỏ lẻ,...) trên địa bàn sẽ được công ty hỗ trợ vốn để đầu tư ban đầu. Trong quá trình sản xuất, nuôi trồng, tất cả những yếu tố kỹ thuật, chăm sóc, vệ sinh chuồng trại... đều thực hiện nghiêm ngặt theo quy định của công ty nhằm tạo ra chất lượng sản phẩm tốt nhất. Những hộ nông dân này nhận được sự hỗ trợ trực tiếp từ Công ty như thu mua sữa và chè với mức giá ưu đãi, bảo hiểm cho chăn nuôi... Còn những hộ nông dân hoạt động theo hình thức tự do, nhỏ lẻ thì hiệu quả kinh tế chỉ đáp ứng một phần cho cuộc sống tại chỗ, chưa mở rộng quy mô và thị trường tiêu thụ. 
Ngoài các chính sách trên, ở Mộc Châu còn có một số kênh thực hiện hoạt động CGKQNC như Trạm Khuyến nông; Hệ thống nghiên cứu triển khai của Viện, trường; Tổ chức Phi chính phủ tài trợ; Doanh nghiệp...

2.2. Nhũng hạn chế của việc chuyển giao kết quả nghiên cứu trong nông nghiệp huyện Mộc Châu

- Nhu cầu của thị trường:

+ Đối tượng chủ yếu của ngành nông nghiệp là người nông dân, với thu nhập thấp so với những đối tượng khác trong xã hội, vì vậy những kết quả nghiên cứu của các tổ $\mathrm{KH} \& \mathrm{CN}$ khó có thể bán cho họ.

+ Đa số chúng ta mang tâm lý tin tưởng công nghệ nhập khẩu từ nước ngoài. Đây cũng là trở ngại cho việc $\mathrm{CGKQNC}$ khoa học từ các tổ chức KH\&CN vào sản xuất, kinh doanh. Nếu công nghệ không có gì vượt trội hoặc giá thành cao thì rất khó cạnh tranh với công nghệ nhập từ nước ngoài. Bên cạnh đó, doanh nghiệp thì cần đổi mới những thực tế trong sản xuất, còn kết quả nghiên cứu lại mang tính hàm lâm, không thực tiễn. Điều này gây nên khoảng cách giữa nghiên cứu khoa học và sản xuất kinh doanh.

- Cán bộ quản lý nhà nước về lĩnh vực KH\&CN của huyện Mộc Châu phải kiêm nhiệm thêm những nhiệm vụ khác nên giải quyết các công việc sự vụ đã chiếm nhiều thời gian, không thể chuyên tâm cho lĩnh vực cụ thể, thông tin và hiệu quả công việc rất hạn chế.

- Đối với doanh nghiệp:

Doanh nghiệp khó có thể cạnh tranh với các tổ chức khác như viện, trường để thực hiện hoạt động CGKQNC bởi vì:

+ Năng lực cán bộ: Cán bộ xây dựng chính sách ở các tồ chức, viện, trường thì có điề̀u kiện về cả trình độ nghiên cứu và cơ sở vật chất, trong khi đó doanh nghiệp tại huyện năng lực thông tin về hoạt động $K H \& C N$ còn thấp.

+ Cơ sở vật chất: doanh nghiệp thì thường gắn liền với lợi nhuận, họ quan tâm và đầu tư nhiều cho hoạt động sản xuất chứ chưa đầu tư đến việc nghiên cứu khoa học, cơ sở vật chất để phục vụ hoạt động sản xuất thử nghiệm còn thấp kém. Huyện Mộc Châu hiện nay có một số doanh nghiệp khoa học như Công ty Cổ phần Hoa Nhiệt đới (nghiên cứu ứng dụng công nghệ cao Hoa lili, Ac - ti - sô), Công ty TNHH Việt Nhật (nghiên cứu chuyên sâu về giống Dâu tây)...

+ Hỗ trợ vốn: Hoạt động CGKQNC gặp phải không ít khó khăn cũng vì tính chất đặc thù (tính mới và tính rủi ro) của kết quả nghiên cứu khoa học. Mỗi kết quả nghiên cứu đều mang tính mới, chưa được ứng dụng rộng rãi trong thực tiễn, vì vậy chúng luôn mang tính rủi ro, có thể thành công hoặc cũng có thể thất bại. Vì vậy, doanh nghiệp sẽ không dám mạo hiểm đầu tư cho hoạt động này nếu không được sự hỗ trợ từ nhà nước.

\section{Quan điểm về chính sách đổi mới thúc đẩy hoạt động chuyển giao kết quả nghiên cứu trong nông nghiệp}

Một là, đầu tư cho đổi mới công nghệ, thúc đẩy CGKQNC vào nông nghiệp phải trở thành nhu cầu cấp thiết của doanh nghiệp, các nông trại và các hộ nông dân sản xuất nông nghiệp.

Hai là, tạo sự đồng bộ trong các cơ chế, chính sách thúc đẩy $\mathrm{CGKQNC}$ bằng việc thực hiện nhiều chính sách khác nhau để tạo động lực đầu tư, sử dụng các công cụ chính sách hỗ trợ cần thiết cho các chủ thể (doanh nghiệp, nông dân...), đồng thời phối hợp chặt chẽ với các cấp, các ngành trong việc thực hiện chính sách sao cho phù hợp với từng điều kiện của địa phương.

Ba là, Nhà nước cần đầu tư đồng bộ cơ sở hạ tầng, kỹ thuật phục vụ cho hoạt động CGKQNC vào nông nghiệp một cách thống nhất, hợp lý, tránh lãng phí các nguồn lực.

Bốn là, đối tượng thụ hưởng chính sách là người dân nên chính sách phải xuất phát từ nhu cầu của người dân. Để thúc đẩy $\mathrm{CGKQNC}$ trong nông nghiệp, nhất thiết phải gắn liền với đào tạo nâng cao năng lực tiếp nhận thông tin, 
cách sử dụng kết quả nghiên cứu sao cho đem lại hiệu quả nhất.

Năm là, Mộc Châu là huyện miền núi, sống dựa vào sản xuất nông nghiệp. Nông nghiệp của huyện đóng vai trò quan trọng đối với sự phát triển kinh tế - xã hội chung của toàn tỉnh. Nhà nước và chính quyền địa phương cần có những chính sách ưu tiên, khuyến khích CGKQNC trong lĩnh vực nông nghiệp, trước hết là phục vụ nhu cầu thiết yếu của người dân tại địa phương, sau là định hướng mở rộng thị trường trong và ngoài nước.

Khi bàn về vai trò của hoạt động CGKQNC trong lĩnh vực nông nghiệp, chúng ta không chỉ nghĩ đơn thuần đến chủ thể chuyển giao và bên nhận chuyển giao, mà cần tìm hiểu, khảo sát và đánh giá thị trường một cách khách quan, thực tế bởi vì kết quả cuối cùng của nông nghiệp là ra thị trường, đến tay người tiêu dùng. Một chủ thể đóng vai trò quan trọng trong việc thúc đẩy CGKQNC trong nông nghiệp là doanh nghiệp. Để hỗ trợ cho doanh nghiệp phát triển hoạt động CGKQNC, Nhà nước cần có những chính sách đổi mới cụ thể như hỗ trợ vay tài chính, giảm thuế, tạo điều kiện cho doanh nghiệp phát triển quy mô sản xuất, đầu tư trang thiết bị hiện đại cho quá trình chế biến và hỗ trợ tổ chức những sàn giao dịch để doanh nghiệp giới thiệu, quảng bá sản phẩm của mình đến người tiêu dùng...

\section{Giải pháp nâng cao vai trò của doanh nghiệp trong chuyển giao kết quả nghiên cứu vào nông nghiệp ở huyện Mộc Châu, tỉnh Sơn La}

\section{- Chính sách ư đãi thuế}

Mục tiêu chung của chính sách này là nhằm thu hút vốn đầu tư, ưu tiên phát triển vùng, lĩnh vực cụ thể, giải quyết nhu cầu việc làm cho người lao động, khuyến khích phát triển doanh nghiệp. Uu đãi thuế có những hình thức như sử dụng thuế suất tiêu chuẩn thấp, thuế suất ưu đãi, miễn toàn bộ hoặc một phần thuế thu nhập doanh nghiệp, khấu hao nhanh... Chính sách ưu đãi thuế hợp lý mang lại nhiều lợi ích cho doanh nghiệp. Việc giảm thuế sẽ giúp doanh nghiệp nâng cao khả năng cạnh tranh với doanh nghiệp khác, có nguồn tài chính ổn định để đầu tư cho sản xuất và dành nhiều hơn cho hoạt động đổi mới công nghệ phục vụ sản xuất.

- Chính sách thúc đẩy năng lục đổi mới công nghệ của doanh nghiẹp

Trong điều kiện còn gặp nhiều khó khăn về tài chính nên các doanh nghiệp trên địa bàn huyện Mộc Châu khó đầu tư để đổi mới công nghệ. Vì vậy, nhà nước cần có thêm những chính sách hỗ trợ, khuyến khích, tạo mọi điều kiện có lợi nhất để giúp doanh nghiệp đầu tư đổi mới công nghệ. Nguồn vốn đầu tư cho đổi mới công nghệ có thể từ nhiều nguồn khác nhau như ngân sách nhà nước, vốn của doanh nghiệp, vốn của các tổ chức khác... Số lượng doanh nghiệp nhỏ và vừa ở Mộc Châu chiếm tỷ lệ lớn. Những doanh nghiệp này có quy mô nhỏ, quy trình sản xuất đơn giản, do nguồn vốn hạn chế nên các doanh nghiệp thường gặp khó khăn trong việc nghiên cứu, đổi mới sản phẩm hoặc quy trình công nghệ. Mặc dù số doanh nghiệp có khả năng đầu tư cải tiến, đổi mới công nghệ còn hạn chế nhưng có thể coi đây là những tín hiệu tích cực của các doanh nghiệp trong quá trình tìm đến những công nghệ mới, tiên tiến, nhằm đáp ứng nhu cầu sản xuất. Và cũng là hướng đi cần thiết để các doanh nghiệp có thể vươn tới sự bền vững.

- Chinh sách thúc đẩy mối liên kết giũua doanh nghiệp và nhà nghiên cứu

Chiến lược phát triển KH\&CN Việt Nam giai đoạn 2011 - 2020 đặt ra mục tiêu năm 2015 sẽ có 3.000 doanh nghiệp KH\&CN và năm 2020 là 5.000 doanh nghiệp khoa học và công nghệ [4]. Nhưng với thực tế kết quả nghiên cứu khoa học hiện nay, rất khó để đạt được mục tiêu này vì có rất ít đề tài nghiên cứu được ứng dụng vào sản xuất, kinh doanh dưới hình thức doanh nghiệp KH\&CN.

Nhà nước cần xây dựng chính sách ưu tiên cho doanh nghiệp, doanh nhân thực hiện hoặc phối hợp với các cơ quan khoa học thực hiện 
các đề tài, dự án KH\&CN cấp nhà nước, cấp tỉnh thiết thực, góp phần thúc đẩy phát triển kinh tế - xã hội, an ninh - quốc phòng của địa phương. Đồng thời, hỗ trợ kinh phí cho việc thực hiện đề tài, dự án nghiên cứu, ứng dụng tiến bộ khoa học, công nghệ mới phục vụ sản xuất kinh doanh của doanh nghiệp, doanh nhân.

Bên cạnh đó, cơ quan quản lý nhà nước về $\mathrm{KH} \& \mathrm{CN}$ cần xây dựng cơ sở dữ liệu và báo cáo về nhu cầu ứng dụng tiến bộ $\mathrm{KH} \& \mathrm{CN}$ ở các ngành, lĩnh vực của địa phương. Để thực hiện được nhiệm vụ này, cần có sự vào cuộc của cả hệ thống quản lý nhà nước về $\mathrm{KH} \& \mathrm{CN}$. Các báo cáo về nhu cầu ứng dụng các tiến bộ $\mathrm{KH} \& \mathrm{CN}$ của cơ quan quản lý nhà nước là một trong những cơ sở quan trọng giúp cho cá nhân, tổ chức KH\&CN hình thành các ý tưởng nghiên cứu hướng nhiều hơn vào thị trường, đồng thời đây cũng một tài liệu tham khảo cho việc mua hay đặt hàng của Nhà nước đối với các tổ chức $\mathrm{KH} \& \mathrm{CN}$.

- Chính sách phát triển thị truoòng, tạo môi truờng tốt cho đầu ra sản phẩm nông nghiệp

Nghiên cứu thị trường một cách khoa học và cẩn thận là việc cần thiết phải làm hiện nay. Hoạt động này cần có sự vào cuộc của các ban, ngành, các chuyên gia phân tích và dự báo thị trường [5]. Việc xác định mặt hàng nông sản nào cần sản xuất và với quy mô như thế nào rất quan trọng. Để tránh tình trạng sản xuất ồ ạt, không tiêu thụ được thì phải lấy nhu cầu thị trường làm căn cứ để dự báo. Bên cạnh đó, doanh nghiệp là nhân tố quan trọng trong việc phát triển thị trường. Hoạt động CGKQNC cần mở rộng liên kết giữa người dân và doanh nghiệp, tạo điều kiện có lợi cho cả hai bên, tránh được áp lực cạnh tranh từ các chủ thể kinh tế khác.

Ổn định đầu ra thị trường là một việc cũng rất quan trọng. Hoạt động sản xuất nông nghiệp muốn ổn định thì cần phải liên kết giữa người sản xuất với các đơn vị như cơ sở chế biến, doanh nghiệp, hợp tác xã sản xuất... Những năm trước đây, hoạt động liên kết này chưa được quan tâm nhiều nên những hộ nông dân sản xuất chỉ mang tính chất nhỏ, lẻ, chưa mạnh dạn đầu tư với quy mô lớn. Khi có chính sách hỗ trợ từ nhà nước cũng như các doanh nghiệp, người dân đã mạnh dạn đầu tư sản xuất lớn hơn vì được đảm bảo đầu ra cho nông sản.

\section{- Chính sách nguồn nhân lục}

Phát triển nguồn cán bộ nghiên cứu thị trường là một định hướng quan trọng của huyện Mộc Châu. Bởi vì, việc sản xuất nông nghiệp mang tính rủi ro cao, phụ thuộc vào nhiều yếu tố. Thực tế ở các địa phương khác cho thấy, việc không nghiên cứu nhu cầu thị trường đã dẫn đến người dân năm nay thấy được mùa thì năm sau tiếp tục sản xuất với quy mô lớn hơn, hàng hóa không tiêu thụ được đã gây thiệt hại đáng kể cho người dân. Việc nghiên cứu nhu cầu thị trường giúp định hướng cho người dân sản xuất phù hợp. Bên cạnh đó, KQNC trong nông nghiệp bao gồm cả những tiến bộ về khoa học và đưa ra công nghệ mới. Vì vậy, cần đào tạo, hướng dẫn cho người dân nắm được nguyên lý hoạt động của máy móc, thiết bị.

\section{- Chính sách thúc đẩy mối liên kết giữa doanh nghiệp và người dân}

Thúc đẩy mối liên kết giữa doanh nghiệp và người dân là một định hướng quan trọng trong hoạt động của tổ chức doanh nghiệp. Các doanh nghiệp lớn ở Mộc Châu như Công ty Cổ phần Giống bò sữa Mộc Châu, Công ty Cổ phần Chè Mộc Châu, Công ty chè Cờ đỏ Mộc Châu... hoạt động theo hình thức vệ tinh. Người dân cùng tham gia hoạt động sản xuất dưới sự quản lý chặt chẽ của doanh nghiệp để đem lại hiệu quả nhất. Doanh nghiệp cũng rất chú trọng đến hoạt động đổi mới công nghệ. Ngoài những kết quả nghiên cứu trong nước có tính khả thi, phù hợp với điều kiện của doanh nghiệp, công ty còn nhập khẩu các công nghệ tiên tiến trên thế giới nhằm chuyên môn hóa dây chuyền sản xuất, đem lại hiệu quả cao cả số lượng và chất lượng. Công ty cần kết hợp với chính quyền địa phương quy hoạch, hình thành vùng sản xuất tập trung với quy mô lớn, tạo mọi điều kiện để nông dân tham gia xây dựng và thực hiện kế 
hoạch, công ty cũng cần có những chính sách hỗ trợ thiết thực hơn để hộ nông dân yên tâm sản xuất.

\section{Kết luận}

Việc xây dựng và ban hành các chính sách hỗ trợ ứng dụng và chuyển giao tiến bộ KH\&CN vào lĩnh vực nông nghiệp được Nhà nước ta rất quan tâm. Sơn La là một tỉnh thuộc vùng Tây Bắc, là nơi có vị trí rất quan trọng về tiềm lực kinh tế, an ninh quốc phòng và tài nguyên khoáng sản. Trong lĩnh vực nông nghiệp, đã có rất nhiều chính sách hỗ trợ chuyển giao các kết quả nghiên cứu như chuyển giao giông cây trồng, giống vật nuôi, kỹ thuật trong thu hoạch, dây chuyền chế biến nông sản... Tuy đã đạt được những thành tựu đáng kể nhưng hoạt động này vẫn chưa được nhiều doanh nghiệp cũng như người dân tiếp nhận và hưởng ứng. Doanh nghiệp đóng vai trò then chốt trong việc thu hút đầu tư, mở rộng thị trường tiêu thụ hàng nông sản, là đầu mối chính và quan trọng của việc $C G K Q N C$ vào trong nông nghiệp. Để hỗ trợ cho doanh nghiệp phát triển hoạt động CGKQNC, Nhà nước cần có những chính sách đổi mới cụ thể như hỗ trợ vay tài chính, giảm thuế, tạo điều kiện cho doanh nghiệp phát triển quy mô sản xuất, đầu tư trang thiết bị hiện đại cho quá trình chế biến và hỗ trợ tổ chức những sàn giao dịch để doanh nghiệp giới thiệu, quảng bá sản phẩm của mình đến người tiêu dùng... Bên cạnh những chính sách trên, chính sách đào tạo phát triển nguồn nhân lực cũng rất cần thiết. Kết quả nghiên cứu là những tiến bộ trong $\mathrm{KH} \& \mathrm{CN}$ được ứng dụng trong hoạt động đời sống hàng ngày. Để khai thác được những tiến bộ $\mathrm{KH} \& \mathrm{CN}$ đó cần đào tạo, nâng cao năng lực làm chủ $K H \& C N$, giúp cán bộ quản lý nhà nước, người dân cũng như doanh nghiệp nắm bắt được những thông tin $\mathrm{KH} \& \mathrm{CN}$ phù hợp với nhu cầu của mình.

\section{Tài liệu tham khảo}

[1] Son La achieved high results in the implementation of the 7th Resolution (10th plenum) on agriculture, farmer and rural https://www.most.gov.vn/vn/tin-tuc/14419/son-ladat-ket-qua-cao-trong-thuc-hien-nghi-quyet-trunguong-7-khoa-x-ve-nong-nghiep--nong-dan--nongthon.aspx (accessed July 25th 2019) (in Vietnamese).

[2] High-tech agriculture development in Moc Chau district http://www.baosonla.org.vn/vi/baiviet/phat-trien-nong-nghiep-cong-nghe-cao-omoc-chau-28930 (accessed July 25th 2019) (in Vietnamese).

[3] Ngo Thi Phuong Quy, Innovation policy aiming to transfer research results in agriculture in Northwest ethnic minority and mountainous areas (Case study in Moc Chau district, Son La province), Master thesis, 2015 (in Vietnamese).

[4] Decision of Prime Minister of Vietnam, Approving the Science and Technology development strategy for the period 2011-2020, No. 418 / QD-TTg, April 11 st 2012 (in Vietnamese).

[5] Pham Van Dung, The development of science and technology market, National Political Publishing House of Vietnam, Ha Noi, 2010 (in Vietnamese). 